\title{
Vestígios, permanências e continuidades
}

\section{Luís Soares Carneiro}

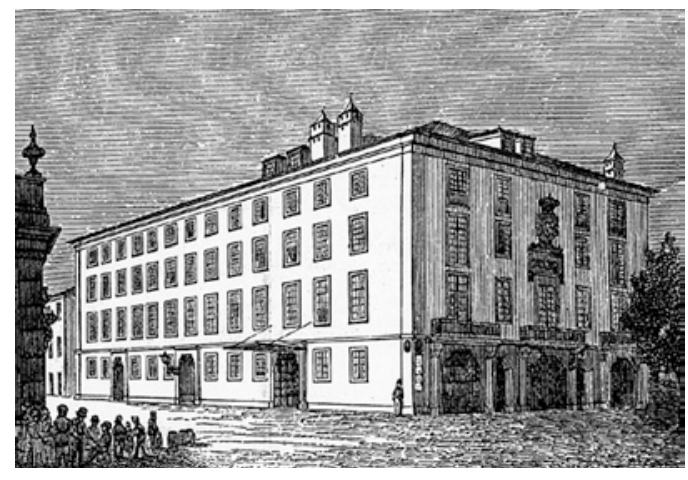

\section{Palimpsesto}

As noções combinadas de permanência e de continuidade constituem, em arquitectura e em urbanismo, não só um poderoso factor de construção da forma mas também da sua leitura, explicação e compreensão. Entre os arquitectos, a ideia de palimpsesto, de permanente reescrita do existente, originalmente aplicada às morfologias territoriais e urbanas num texto famoso de André Corboz, foi intensamente apropriada.

0 território, sobrecarregado como está de vestígios e leituras passadas, assemelha-se mais a um palimpsesto. Para integrar novos equipamentos, para explorar de forma mais racional certos espaços, é muitas vezes indispensável alterar-Ihe a substância de modo irreversível. Mas o território não é uma embalagem perdida nem um produto de consumo substituivel. Cada um é único, e dai a necessidade de "reciclar", de raspar uma vez mais (mas com o maior cuidado possivel) o texto antigo que os homens inscreveram sobre o material insubstituivel dos solos, afim de nele depositar um novo, que responda às necessidades de hoje antes de ser, por sua vez, revogado. Algumas regiões, tratadas de forma demasiado brutal e imprópria, apresentam hoje buracos, como um pergaminho demasiado rasurado. (Corboz 1983, tradução minha)

Correspondia, na altura, a um conjunto de renovadas preocupações com a cidade e com os seus edificios, entendidos como o acumular de formas e de marcas ao longo de extensos períodos de história, que importava entender e recuperar, depois de um longo período no qual os arquitectos e urbanistas do século XX tinham feito da tabula rasa a premissa inicial.

Como um palimpsesto, os edificios antigos em particular, mas não só, acumulam e integram em si múltiplas camadas de vestígios, de traços, de sinais e de memórias que, normalmente esquecidos e por vezes encobertos,

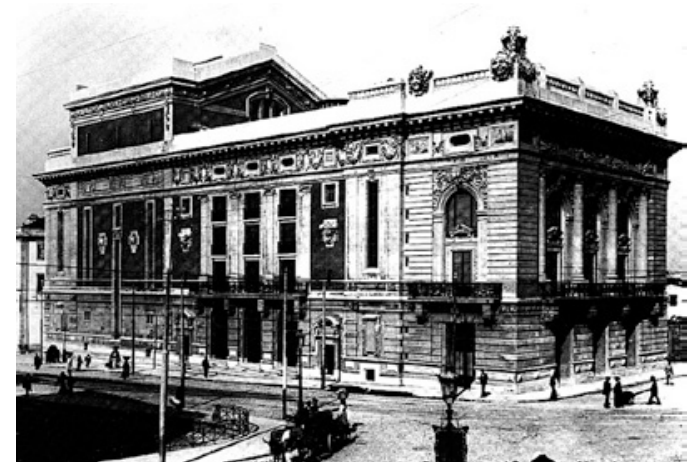

0 primeiro Teatro de São João Fonte: Gravura do exterior por Nogueira da Silva [Oliveira 1985: $\left.n^{\circ} 146\right]$ [Alvão 1984: 123 - "O novo teatro de São João"].

permanecem aguardando descodificação. Nos parcelamentos, nas implantações, nos traçados viários, na integração de fundações, paredes e materiais, assim como nas múltiplas e diversas recomposições programáticas, funcionais e formais, existem quase sempre elementos que permanecem e explicita ou insidiosamente vão influindo nas novas formas.

0 mesmo se passa, cumulativamente, com as componentes culturais que integram a arquitectura: agenciamentos, organização, formas, decorações, gostos, modas, modos de fazer, tecnologias e estratégias compositivas.

No conjunto das duas - vestígios materiais e culturais - se criam e recriam, constantemente, quer os novos edifícios quer, sobretudo, a reconstrução dos antigos.

\section{Teatro de São João}

0 actual Teatro é um dos melhores e maiores teatros clássicos portugueses. Erguido entre 1910 e 1920 com projecto do notável arquitecto que foi José Marques da Silva (1869-1947) (v. Cardoso 1997), insere-se estilisticamente nas correntes ecléticas de finais do século $\mathrm{XIX}$, misturando com mestria o estilo Louis XVI e o estilo Napoleón III, com uma visão da organização planimétrica e da composição arquitectónica substantivamente baseadas nos ensinamentos da École des Beaux-Arts de Paris, onde Marques da Silva se tinha formado.

Mas estes factos gerais estão longe da explicação de muitas das formas e das opções projectuais tomadas, as quais pressupõem todo um conjunto de circunstâncias, de elementos, de pré-existências materiais e imateriais que influiram e encaminharam as formas daquele edificio para o resultado que conhecemos hoje.

Embora seja frequente referir os mais de duzentos anos do Teatro de São João, confunde-se frequentemente a instituição com a forma, pois, antes do actual edifício
Luís Soares Carneiro é arquitecto e professor na Faculdade de Arquitectura da Universidade do Porto. 
mplantação do primeiro Teatro de São João sobre as antigas muralhas medievais do Porto [Esquema do Autor].

Planta do piso da Tribuna do primeiro

Teatro de São João

[Reconstituição do Autor].

Diagrama gerador da composição do primeiro

Teatro de São João

[Esquema do Autor].
- hoje activo como TNSJ - existiu um outro, com o mesmo nome e no mesmo local, que marcou intensamente a cidade e a vida cultural do século XIX portuense. Este primeiro teatro, erguido entre 1796 e 1798 , com projecto do italiano Vicenzo Mazzoneschi "architetto romano" (v. Ferrão 1999; Mendonça 2004), manteve-se activo até 1908, quando foi destruido por um incêndio.

0 que determinou as formas do primeiro, o que determinou as formas do segundo, o que do primeiro fo repassado para o segundo por contingência e o que foi repassado por vontade, são algumas das questões que aqui abordamos.

\section{0 primeiro Teatro}

0 Teatro de São João deve o seu nome ao então Príncipe D. João, futuro Rei D. João VI, tanto como homenagem pessoal como por estratégico pedido de patrocínio para a obtenção de terreno público e autorização de construir

A edificação do Teatro de S. Carlos, em Lisboa, realizada em 1782-83, tinha criado um novo padrão para os teatros portugueses, na dimensão, na qualidade e na sofisticação da concepção, tornando obsoletos todos os locais de espectáculos então existentes. Tal precedente gerou, no Porto, a "segunda capital do reino", um notório espírito de emulação. 0 paralelismo entre os dois casos é evidente e significativo. Para as novas necessidades de sociabilização da segunda metade de setecentos e para o grande sucesso público do "teatro italiano" - designação então corrente dos espectáculos de ópera - impunha-se a existência de novos teatros que solucionassem não só o espaço materia da realização teatral, mas que oferecessem também um novo quadro para as necessidades de encontro social alargado - extravasando os estreitos limites das "assembleias" caseiras -, teatros onde, a pretexto da ópera, se convivia se dançava, se jogava, se criavam oportunidades e negócios, se cruzava uma sociedade em mutação onde se misturava a nova burguesia com a velha nobreza. Mais ainda, no caso do S. Carlos, aproveitava-se para cruzar uns e outros com a família real, cumprindo o propósito de Pina Manique o todo-poderoso Intendente da Polícia, de "conciliar o amor dos vassalos para os príncipes, e o destes para aqueles" (Carneiro 2005), num ambiente político de evidente alarme face aos eventos revolucionários em Paris. Este mesmo Pina Manique foi, ao contrário da ideia feita e corrente de que teria sido "um grupo de burgueses da praça de Lisboa" a promover a realização do teatro - e como mostramos já (Carneiro 2003: vol. I, cap. VI, 158 ss.) - 0 efectivo autor da ideia e o líder do processo do teatro lisboeta.

Identicamente, ao mesmo entusiasmo pela ópera, ao mesmo desejo de sociabilização e a mecanismos de poder semelhantes, foi também o "Desembargador, Corregedor e Provedor da Comarca do Porto" Francisco de Almada e Mendonça (1757-1804), o equivalente de Pina Manique na cidade nortenha, a promover e a dinamizar a ideia de um novo teatro no Porto. E mesmo sem a presença física de "Suas Magestades", nas ocasiões solenes abria-se a
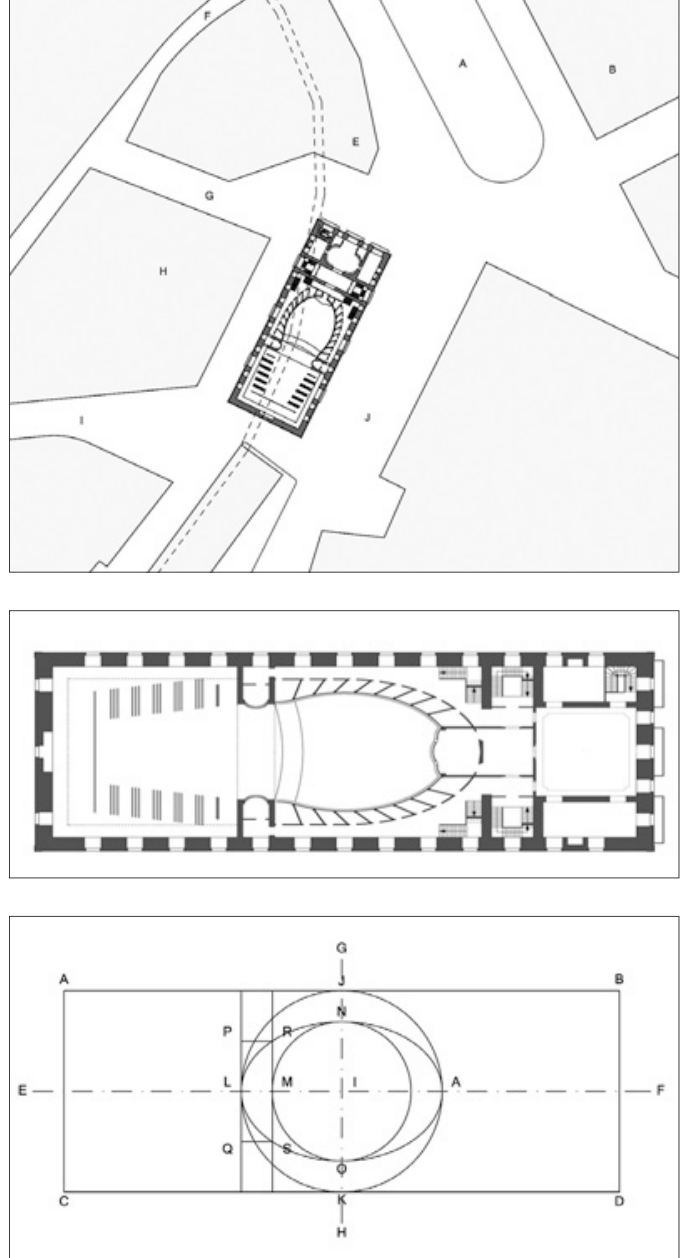

cortina da grande tribuna real que, à semelhança de Lisboa dominava a sala de espectáculos, curvando-se todo o público, ao som do hino, perante a efígie real.

Francisco de Almada, não só lançou a ideia como a dinamizou com a criação de uma sociedade por acções que iria promover a construção e assegurar o necessário financiamento, com base numa cartilha ideológica de raíz iluminista que tinha já estado na origem, em 1771, do Alvará Régio que criou a efémera Sociedade dos Teatros Públicos da Corte (v. Sequeira:1933). Genericamente, argumentava-se com base nas ideias de progresso, de civilização e de moralidade social alegadamente trazidas pela frequência dos teatros, buscando a "erradicação dos costumes mouriscos" como referia Jácome Ratton, anos antes, nas suas "Memórias" (1813: 349).

$\mathrm{Na}$ generalidade das cidades existe um sistemático fenómeno de concentração de lugares de espectáculos com regras particulares de sucessão e de proximidade (Carneiro 2009). Assim, não surpreende que o Teatro de São João não só tenha sido o principal e o mais antigo elemento do núcleo de salas de espectáculos da zona da Batalha o mais importante na cidade do Porto - mas que também esse local tenha sido escolhido relativamente próximo do seu antecessor, o pequeno e pobre Teatro do Corpo da Guarda - de facto uma simples adaptação - construído em 1762 nas cocheiras da Casa do Duque de Lafões.

Ainda assim, a localização urbana do Teatro de São João foi estrategicamente escolhida, estando ainda hoje bem posicionado. A colocação do Teatro junto a uma das 

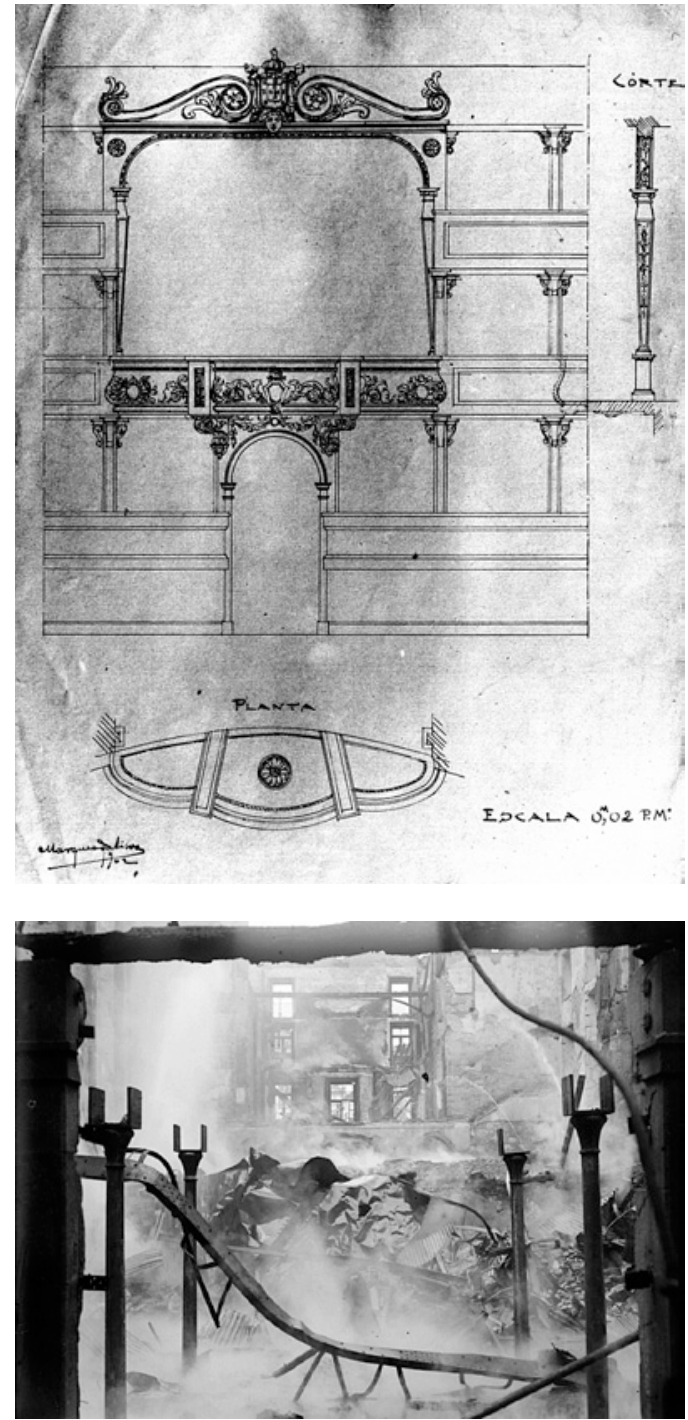

portas da muralha erigida no séc. XIV, relacionava-o com um conjunto de arruamentos que, tanto ao longo do perimetro amuralhado como para o seu interior, mas também e sobretudo para o seu exterior, pelas estradas que ligavam o casco antigo ao vasto território que o crescimento urbano posterior viria a ocupar e consolidar, assegurando a sua boa acessibilidade.

Ainda que hoje o crescimento da cidade tenha gerado outras polaridades e uma dimensão inimaginável para aquela época, se considerarmos apenas o "centro" da cidade consolidada, ou seja, de raíz pré-moderna, o Teatro continua a ter uma posição de significativa centralidade, razão pela qual, quando da sua reconstrução, em inícios do séc. XX, não apenas herdou mas também garantiu uma posição de grande centralidade e excelentes acessibilidades relativamente a boa parte da cidade.

A implantação do Teatro original foi muito particular, tirando partido de um conjunto de leis que serviam de instrumento à política Almadina ${ }^{1}$ de renovação e desenvolvimento urbano, entre as quais aquela que cedia gratuitamente os terrenos e a pedra da muralha a quem se comprometesse a ali construir, afim de abrir o velho burgo a uma expansão julgada necessária e urgente. Com esta possibilidade, o teatro foi construido exactamente sobre e ao longo da muralha, incluindo a expropriação de algumas casas que se realizaram para acertar e regularizar o terreno.

Os burgueses portuenses, atentos às possibilidades de negócio, não só agarraram a oportunidade como forçaram o arquitecto a alterar o projecto originalmente apresentado, obrigando-o à realização de uma segunda versão, de planta mais estreita e mais longa, a fim de conquistar mais terreno e obter maior quantidade de pedra (Carneiro 2003: vol. I, cap. VII). Esta circunstância, de origem legal e fundamento empresarial, determinaria não só o terreno ocupado pelo Teatro mas uma peculiar proporção comprimento/largura, absolutamente marcante na forma do primeiro edifício mas também, como veremos, da sua versão actual.

0 corpo construído do teatro era efectivamente estreito. E isso obrigou a duas opções de projecto que viriam a tornar-se peculiaridades do edifício. Por um lado, a boca de cena era relativamente reduzida, por outro a sala era alta, gerando um arco de cena alto e estreito. Mais ainda, para assegurar circulações no piso térreo entre a zona do palco e a zona da entrada, houve que criar dois corredores ao longo das fachadas laterais, de ambos os lados da plateia, o que teve como dupla consequência uma correspondente subida de cota das frisas, em relação ao que era corrente na época, e o consequente envolver a plateia com paredes altas.

Coerente com a sua estratégia de emulação com o S. Carlos, o São João recuperou daquele dois elementos particulares. A curva da sala, de analema elíptico inteligentemente utilizada no S. Carlos por Costa e Silva, que a tinha ido buscar ao tratado de Pierre Patte (1782), foi recuperada por Mazzoneschi que tinha conhecimento directo das qualidades acústicas do teatro lisboeta por ali ter trabalhado como cenógrafo. Mas se Mazzoneschi conhecia e apreciava as qualidades acústicas do S. Carlos, percebe-se que, ao contrário de Costa e Silva, não dominava a teoria, pois ao colocar duas prumadas de grandes camarotes de boca enquadrados por largas pilastras, obrigou ao recuo do palco afastando a posição dos actores/cantores do foco da elipse, reduzindo a eficácia das reflexões do som e piorando as qualidades acústicas, sobretudo para espectáculos de teatro declamado, gerando assim uma certa "especialização operática".

Outra das heranças do S. Carlos foi a existência de uma gigantesca tribuna real que ocupava o espaço de seis camarotes e profusamente decorada. Por detrás desta tribuna, uma saleta quadrada, também muito decorada, destinava-se a descanso e recepção de visitantes, nos intervalos dos espectáculos em que SSMM estivessem presentes.

Mesmo vazios - pois foram relativamente raras as presenças Reais neste Teatro -, o prestígio destes espaços iria perdurar no imaginário dos frequentadores habituais, não obstante nos anos oitenta do séc. XIX, numa das renovações periódicas do edificio e num quadro de crescente contestação da monarquia, ter a tribuna sido transformada

\section{Levantamento da frente da "Tribuna Real" do primeiro Teatro de São João, de 1902, assinado por Marques da Silva [Arquivo da FIMS]}

Incêndio do primeiro Teatro de São João. Fonte: Fotografia de Aurélio Paz dos Reis, CPF, Cota: Cx 363, APR4957.

${ }^{1}$ A influência na forma e nos destinos da cidade da Junta das Obras Públicas (depois de 1763), dirigida por João de Almada e Melo (1703-1786) e depois pelo seu filho Francisco de Almada e Mendonça (1757-1804), teve grande importância na forma urbana portuense, pela implementação de um conjunto de acções de renovação da cidade, tais como o derrube das muralhas, a construção de novas ruas e praças e o ordenamento ou renovação de espaços urbanos existentes que transformaram a cidade medieval e abriram caminho para a expansão oitocentista. (v. Ferrão 1989). 
Planta da $1^{\text {a }}$ ordem da sala

do actual Teatro de

São João

Redesenho do Autor]

Planta de lugares

[Patricio 1926].

Interior da sala do actua Teatro de São João

fot. Domingos Alvão [Seabra 1993].

Embora o betão fosse

na altura um materia ainda recente, o pioneiro

da aplicação daquele

material nos teatros

portugueses tinha já sido o Teatro República (antigo

Teatro Rainha D. Amélia, posteriormente Teatro $\mathrm{S}$

Luiz) na reconstrução que

sofreu depois de um grande incêndio, com projecto de Tertuliano

Marques entre em 1914-16. em duplo balcão e a saleta franqueada ao público como extensão do espaço do foyer.

\section{0 segundo Teatro}

0 primitivo São João teve uma vida longa para um teatro da sua geração, onde os incêndios eram frequentes. Ali passaram sobretudo espectáculos de ópera mas também concertos, teatro declamado, conferências, comemorações, celebrações, festividades mundanas e patrióticas, bailes, diversões e pateadas célebres, além dos pequenos escândalos de que a sociedade portuense teve a sua parte.

0 facto é que o Teatro de São João se integrou e entranhou na cidade tornando-se uma referência a múltiplos níveis. Mesmo o surgimento de outros teatros de cariz diverso, ou seja, mais abertos a públicos menos afortunados, de programação mais popular e com estratégias comerciais - o "Príncipe Real", o "Baquet", o "Trindade", o "D. Afonso", o "Carlos Alberto"... - apenas reforçou a sua fama e a clara primazia na hierarquia dos teatros portuenses.

Por isso, quando na madrugada de 11 de Abril de 1908 o teatro ardeu por completo (fig. 9), a cidade sofreu um choque - bem visivel na quantidade e continuidade de lamentos, apelos, notícias e comentários que durante os meses seguintes inundaram os jornais - pelo que de imediato as forças vivas se puseram em marcha para a sua reconstrução.

Apesar das boas vontades o processo não foi fácil. 0 Municipio, alegando problemas financeiros, excluiu-se, e a sociedade de acções responsável pela construção origina - que por um processo de compras e heranças estava concentrada em poucos accionistas - disponibilizando embora o terreno como capital para uma nova sociedade, não tinha meios para promover, só por si, a reconstrução. Acabou por ser organizada uma nova sociedade, por subscrição pública de acções, que avançou com o processo de edificação do Teatro. Realizaram-se dois concursos de projectos, no primeiro dos quais o Júri recusou eleger um vencedor e um segundo que veria José Marques da Silva (que tinha sido jurado no primeiro) emergir como premiado, ficando encarregado pelo desenvolvimento do projecto definitivo e do acompanhamento da obra.

Marques da Silva tinha-se formado em Paris, era professor na Escola de Belas Artes do Porto, tinha trabalhado na autarquia, havia já realizados algumas obras significativas - nomeadamente a Estação de São Bento (1900-1915) e possuía uma relação sólida com a melhor burguesia portuense, constituindo parte dela, o que, independentemente da sua competência e do seu talento, não era de desprezar.

0 processo avançou e a obra iniciou-se em 1910, mas o conjunto de contratempos foi grande. A revolução republicana, a primeira grande guerra, epidemias, dificuldades nas importações, problemas burocráticos, levaram a que a inauguração apenas se fizesse em 1920.

0 resultado iria agradar a todos. 0 novo edifício ganhava uma monumentalidade formal que o seu antecessor não tinha, abandonando a esqualidez arquitectónica das
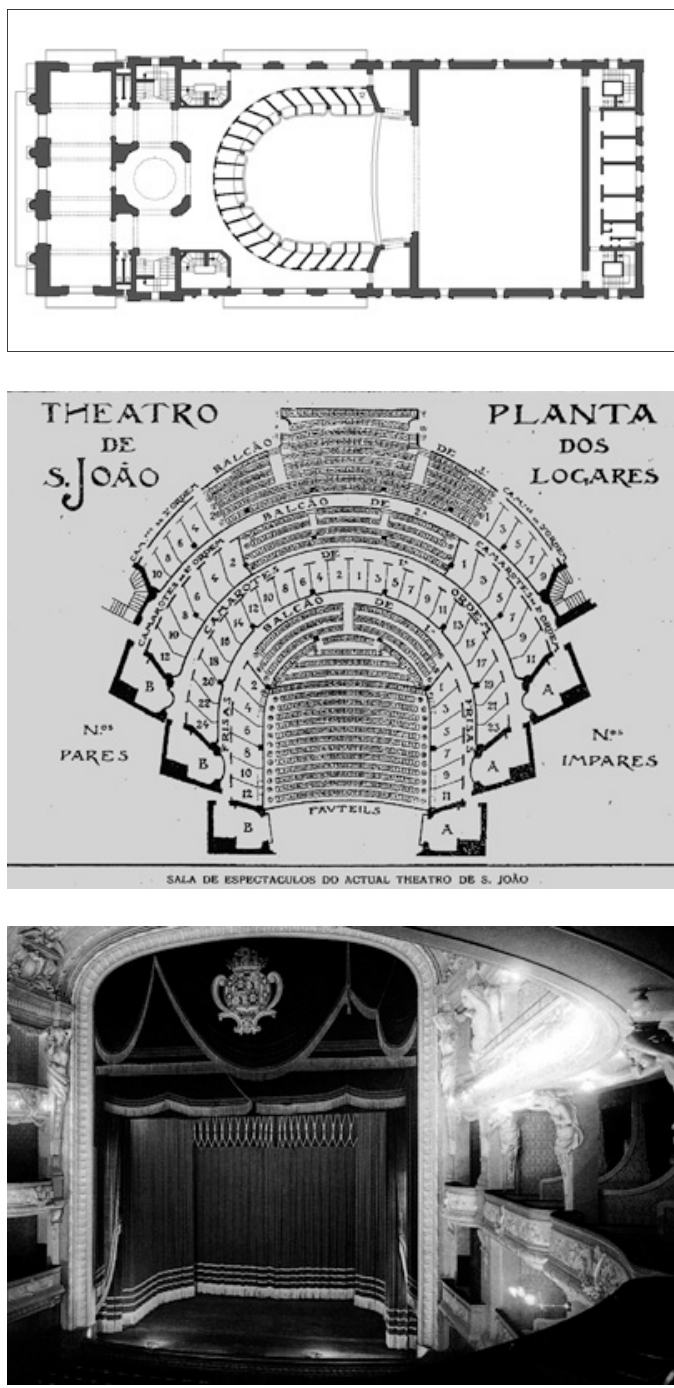

fachadas de linguagem almadina em favor de um tratamento superficial mais vistoso e decorado, embora com moldagens de argamassa e não em pedra. A sua construção interna em paredes de granito e betão ${ }^{2}$ era sólida e incombustivel, a sua organização interna simultaneamente clara e exuberante, a sua disposição da sala ao mesmo tempo clássica e inovadora e, sobretudo, sabia mesclar a memória e o sentido de continuidade do antigo teatro com as transformações inevitáveis, as mudanças necessárias e as inovações convenientes.

Infelizmente, entre o incêndio do antigo teatro e a inauguração do novo o mundo tinha mudado. As confusões políticas e sociais da República, a não concessão de subsídio público para o funcionamento, a crescente importância do cinema, a decadência da velha burguesia, fariam com que o Teatro de São João mudasse de nome para "São João Cine" logo em 1929

Neste contexto, o seu papel como modelo arquitectónico e padrão de gosto seria, naturalmente, muito limitado. 0 próprio Marques da Silva, em 1916 ainda não estava concluído o São João! - no projecto que fez para a reconstrução - nunca realizada - do Teatro da Figueira da Foz (antigo Teatro Principe D. Carlos), também ele desaparecido num incêndio, propunha já uma forma de sala que tendia a aproximar-se do que mais tarde viriam a ser os cine-teatros. 


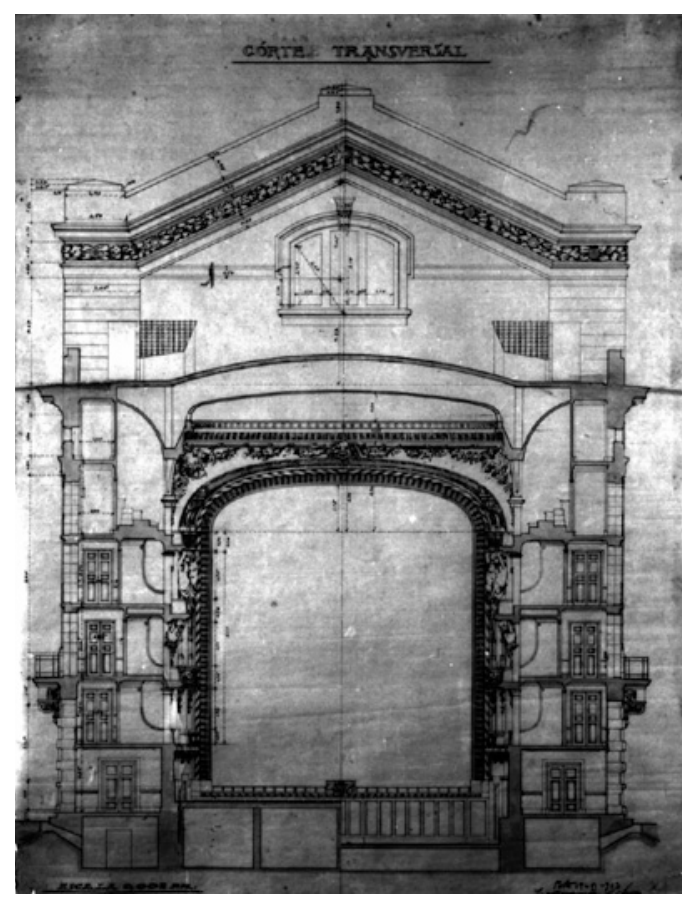

\section{A intencional continuidade}

Interessa observar um conjunto de vestígios e permanências que materializam o sentido de herança e continuidade, tanto circunstancial como cultural, entre o edifício desaparecido no incêndio e o depois construído. E isto tendo em mente que também o primitivo teatro teve as suas influências e raizes, tanto no S. Carlos, como vimos, como na formação e experiência prévia de Vicenzo Mazzoneschi, nomeadamente do seu projecto para o Teatro Principal, em Málaga.

Marques da Silva herdou pois um conjunto de dados concretos, muito precisos, tais como a dimensão do terreno e a sua proporção alongada - um "quadrilongo", saborosa expressão que Sousa Reis tinha usado no seu manuscrito, na descrição do antigo teatro, em $1866^{3}$ - e uma

correspondente e pré-determinada implantação; sendo no entanto verdade que a frente do Teatro foi avançada para respeitar o alinhamento da nova Rua Alexandre Herculano; assim como depois iria beneficiar - em 1924 - do desafogo da fachada principal, quando foi demolida a capela de N. S. da Batalha que sempre tinha constrangido a fachada do primitivo edifício.

Seguindo o edifício anterior, a distribuição das funções retomava a tradição geral desta tipologia teatral, colocando a entrada principal no topo norte e sobre ela o salão nobre, agora renomeado foyer. Na parte central do edifício colocavam-se as escadarias de acesso, os espaços de distribuição e a sala, ficando do lado sul o palco e o volume sobressaliente da sua monumental caixa de cena - uma inovação e diferença substantiva em relação ao teatro primitivo, imposta por uma tecnologia de exploração cénica elaborada ao longo do século XIX, mas apenas introduzida em Portugal, de modo sistemático, no último quartel de 800 - terminando com a colocação dos camarins sobrepostos em pisos em toda a sua fachada sul.

Sendo a sala de espectáculos um dos elementos essenciais de um teatro, Marques da Silva colocou ai um conjunto de sinais de continuidade cuidadosamente misturados com aspectos de inovação. A forma da curva da sala perdia a forma elíptica, entretanto caída em desuso, preterida pela ferradura de tramos rectos, mas recuperava a forma da boca de cena, estreita e alta terminando em arco abatido. Criava uma "corbeille" ou seja, um balcão que se apoia na plateia prolongando-se até ao nivel das frisas, uma inovação importada dos teatros franceses do séc. XIX, mas mantinha uns imponentes camarotes de boca, enquadrados por grandes pilastras trabalhadas que retomavam a forma e disposição do teatro desaparecido. Obviamente eliminava - República oblige! - a tribuna real, substituindo os balcões que aí tinham sido entretanto colocados por balcões corridos nas segunda e terceira ordens. Os camarotes reduziam-se aos da primeira ordem mais as frisas e camarotes laterais das restantes.

Também no projecto de Marques da Silva, tanto pela contingência da estreiteza do terreno como pela memória do antigo edificio, as frisas se apresentavam a uma cota inusualmente alta, para assegurar, sob o seu pavimento, as saidas e os corredores de acesso lateral à plateia, assim como permitir a ligação entre as zonas da frente e das traseiras do teatro, no piso térreo.

Particularmente interessante, é um aparentemente enigmático espaço situado entre os corredores da primeira ordem e o foyer, com duplo pé-direito e decoração reforçada, articulando o corredor de acesso aos camarotes, as saídas das escadas e o eixo de simetria da fachada principal.

Em esquissos de fases muito iniciais do projecto que se conservam na Fundação Instituto Marques da Silva ${ }^{4}$, pode observar-se que o arquitecto atribuiu a esse espaço uma particular atenção quando trabalhou tais desenhos (fig.15). Refira-se que os desenhos feitos à mão livre, sobretudo nas fases preliminares dos projectos, são normalmente reveladores das intenções e preocupações mais profundas, colocadas precocemente em jogo no complexo emaranhado de dados que vão formar e informar a concepção, muito antes de decisões sobre medidas, materiais, sistemas construtivos ou outros elementos característicos de fases mais tardias do projecto entrarem em consideração. Ou seja, Marques da Silva atribuiu a esse espaço, desde o início, uma marca distintiva, significando que ali estava um dos pontos essenciais do projecto, um dado de partida que iria condicionar outros, em sucessão.

Tal preocupação correspondia de facto a uma intenção importante. Referimos anteriormente a existência da saleta anexa à tribuna real no primitivo teatro. E como, em 1888, esta foi franqueada ao público como espaço de acesso aos dois balcões que passaram a ocupar aquela Tribuna. E referimos mesmo que aquela saleta era profusamente decorada. De facto, Marques da Silva destacou este espaço pois com ele desejava evocar a antiga saleta real, tal como dela se recordavam os velhos habituées do São João. Só assim se compreende que nele se tenha recorrido a uma decoração com estípites - um tema decorativo muito corrente em finais do séc. XVIII quando o primeiro Teatro de São João foi construído - mas há muito caído em
Corte transversal do projecto do actual teatro de São João; desenho de Marques da Silva, 191 [FIMS].

3 BPMP, Ms. 1273 Henrique Duarte Sousa Reis, Apontamentos para a verdadeira história antiga e moderna da cidade do Porto.

${ }^{4}$ É uma Fundação instituida pela Universidade do Porto destinada à promoção cientifica, cultural e artistica, e a preservar, conservar, investigar, estudar e divulgar a obra do arquitecto José Marques da Silva, bem como, complementarmente, ao acolhimento de outros fundos relativos à arquitectura e ao urbanismo português e que muito recentemente integrou o acervo documental do Arquitecto Fernando Távora. 
Fotografia do espaço central,

fot. Luis Ferreira Alves. desuso quando o segundo teatro foi edificado.

Quando a decoração utilizada em todo o resto do teatro é dominada em absoluto pelo gosto francês da segunda metade de oitocentos, sem nada a ver com temas decorativos setecentistas de origem espanhola, a estranheza destas estípites ${ }^{5}$ e a sua presença anómala num conjunto coerente e controlado por uma visão única e global, só pode ser interpretada como intencional. Ou seja, Marques da Silva, repôs a forma, a espacialidade e até alguns dos elementos decorativos da desaparecida saleta, tal como ele próprio e os seus coetâneos a tinham conhecido - isto é, reconstituindo um espaço de circulação aureolado ainda pela memória da antiga função. Com isso, Marques da Silva estabeleceu um elemento de continuidade com a memória dos seus clientes e utentes, todos eles, como ele próprio, frequentadores e conhecedores do edifício desaparecido.

Se toda a boa arquitectura é feita de memória e talento - e toda a Arte, como é sabido, é filha de Mnemosine e de Júpiter! - no caso do segundo Teatro de São João, tornase muito claro o modo como alguns dos elementos singulares do conjunto de determinantes da forma do primitivo edifício impuseram a sua presença. Ao conjunto de sinais de continuidade material, agregou-se um outro conjunto de sinais de continuidade cultural, e ainda um outro conjunto de sinais que a experiência e o talento de Marques da Silva, nomeadamente a sua formação, gosto conhecimentos e determinação, aportaram para a resolução da complexa equação que um projecto como o deste Teatro evocou.

\section{Estudar e projectar}

Quando o teatro foi comprado pelo Estado, nos anos noventa do século XX e instituído o TNSJ, foi realizado um conjunto de obras ${ }^{6}$ de melhoramento e actualização técnica, de complemento de programa e de reequipamento, necessários num teatro com setenta anos de vida e que tiveram o mérito de alterar sem perder o essencial.

0 importante numa intervenção de arquitectura, quando se trata de modificar o existente - e toda a arquitectura, enquanto intervenção física e material necessariamente o faz! - é discernir com clareza e inteligência, normalmente também com algum drama, 0 que importa em absoluto preservar e o que vai ter de ser necessariamente transformado para que possa continuar a existir e a funcionar.

Sem haver fórmula ou receita, sempre será essencial
${ }^{5}$ Para o estudo desta

situação e do seu significado para Marques da Silva e para o Teatro de

São João, o estudo aprofundado e o conhecimento dos edifícios e da sua história, a compreensão dos valores materiais e imateriais que eles transportam, assim como dos grupos de utentes que os usaram e voltarão a utilizar no futuro, pois isso constitui, mesmo antes do saber específico da arquitectura entrar em acção, uma parte importante dos dados a ter em conta.

Marques da Silva deixou-nos esta lição bem clara com a sua reconstrução do Teatro de São João. Compreendeu os vestígios, percebeu a necessidade cultural da continuidade,

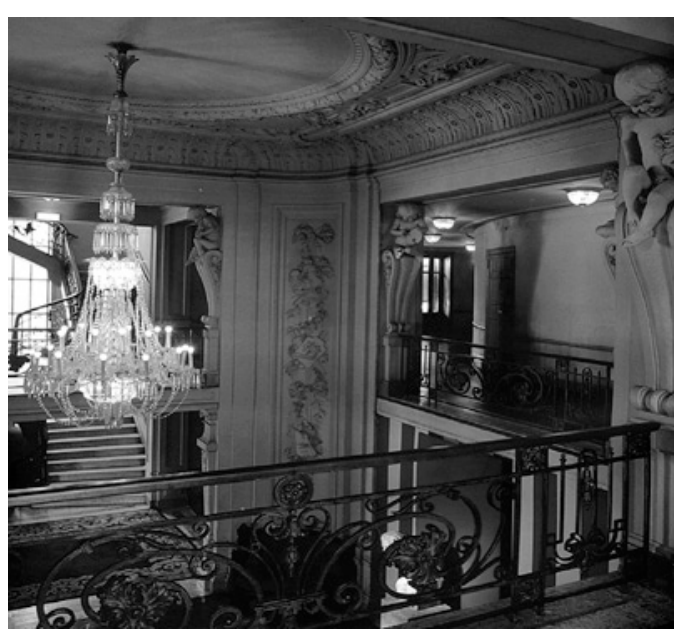

e conjugando isso com o seu próprio saber e talento, determinou, com vigor e acerto, a identidade do novo edificio.

\section{Referências bibliográficas}

ALVÃO, Domingos (1984), A cidade do Porto na obra do fotógrafo Alvão, 1872/1946, Porto, Edição da Fotografia Alvão.

CARDOSO, António (1997), 0 arquitecto José Marques da Silva e a arquitectura no Norte do País na primeira metade do séc. XX Porto, FAUP Publicações.

CARNEIRO, Luis Soares (2003), Teatros portugueses de raiz italiana, Tese de Doutoramento apresentada na FAUP, Porto, Policopiada.

-- (2005), "0 Teatro de S. Carlos, Expoente dos Teatros à Italiana em Portugal", em separata do Programa de sala da ópera Otelo, de Verdi, apresentada no TNSC de 31.10 a 10.11.2005.

-- (2009), Do Teatro de S. João á Casa da Música, texto para o Colóquio Internacional: "(re)Construir Cidades: Cartografias a partir de Marques da Silva", FAUP [no prelo]

-- (2010), A estranheza da Estípite : Marques da Silva e o(s) Teatro(s) de S. João, Porto, Fundação Instituto José Marques da Silva.

CORBOZ, André (1983), "Le territoire comme palimpseste", Diogène, n¹21 Janeiro-Março, pp.14-35.

FERRÃO, Bernardo José (1989), Projecto e transformação urbana do Porto na época dos Almadas, 1758/1813, Porto, FAUP, 2ª ed.

-- (1999), "Os arquitectos que mudaram a face ao Porto, 3. Vicenzo Mazzoneschi", OTripeiro, Série Nova, Ano I, n6, pp.18-19.

MENDONÇA, Isabel Mayer Godinho (2004), "Um projecto de Vincenzo Mazzoneschi: para o primeiro Barão de Quintela, em inícios do século XIX", in Monumentos: Revista semestral de edificios e monumentos nacionais, Lisboa, n² 21, Setembro, pp. 98-107.

OLIVEIRA, Eduardo Pires de (1985), Imagens do Porto Oitocentista, Porto, AHMP/ARPPA, n¹46, "Teatro de S. João, Porto".

PATRíCIO, Padre F.J. (1926), "Tradições do Theatro de S. João", IV, in 0 Tripeiro, $3^{\text {a }}$ série, n¹6, 15/08/1926.

PATTE, Pierre (1782), Essai sur l'architecture théatrale ou de l'ordonnance la plus avantageuse à une salle de spectacles relativemente aux principes de l'optique et de l'acoustique..., Paris.

PIRES, Caldeira (org.), Annuário Commercial de Portugal, Ilhas e Ultramar, 1897.

RATTON, Jacome (1813), Recordaçoens sobre ocurrencias do seu tempo em Portugal, durante o lapso de sessenta e tres anos e meio, alias de Maio de 1747 a Septembro de 1810 [...], Londres, H. Breyer.

SEABRA, Augusto (1993), Ir a S. Carlos, Lisboa, Correios de Portugal.

SEQUEIRA, Gustavo de Matos (1933), Teatro de outros tempos. Elementos para a história do teatro português, Lisboa. 


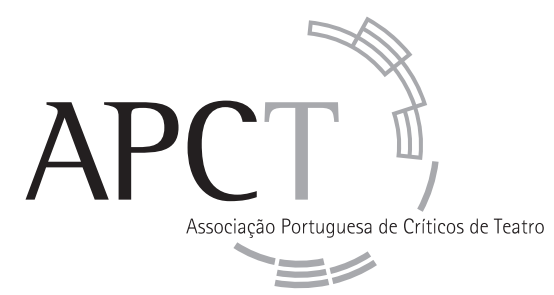

\begin{tabular}{c|l} 
Presidente honorário & Luiz Francisco Rebello \\
Direcção & $\begin{array}{l}\text { Maria Helena Serôdio } \\
\text { João Carneiro } \\
\text { Rui Pina Coelho }\end{array}$
\end{tabular}

Assembleia Geral $\quad$ Alexandra Moreira da Silva Sebastiana Fadda

Conselho Fiscal $\quad$ Ana Isabel Vasconcelos

Mónica Guerreiro

Constança Carvalho Homem

\begin{tabular}{l|l} 
ESTATUTOS & Capítulo Primeiro (Da Associação e dos seus fins)
\end{tabular}

Art. ${ }^{2} .^{\circ}$

A Associação tem por objectivo:

Dignificar, estruturar e responsabilizar a actividade crítica relativa à teoria e prática do teatro, entendendo-se por actividade crítica não só a crítica de espectáculos, mas também tudo aquilo que diga respeito à informação, reflexão e teorização no campo das artes performativas.

\section{Colaboração com Sinais de cena}

A revista está aberta à participação de quem deseje colaborar enviando artigos que julgue corresponderem aos objectivos da publicação e às modalidades enunciadas pelas rubricas existentes. A consulta do sítio da APCT na Internet (www.apcteatro.org) e o contacto por correio electrónico (estudos.teatro@fl.ul.pt) são indispensáveis para conhecer as normas de apresentação dos artigos (dimensão, aspecto gráfico, citações, referências bibliográficas, ilustrações, etc.).

\section{ASSINATURA}

Desejo subscrever os números 17 e 18 da revista Sinais de cena (correspondentes a Junho e Dezembro de 2012), no valor total de $22,00 €$ beneficiando assim de um desconto sobre o preço de venda ao público. Fora do país: Europa $24,00 €$ / Fora da Europa $26,00 €$.

Nome:

Morada:

Código postal: $\quad$ País:

Endereço electrónico:

\begin{tabular}{ll|l} 
Forma de pagamento: $\quad \square$ Vale postal $\quad \square$ Cheque $n^{\circ}$. & Banco \\
\hline
\end{tabular}

(passar à ordem de Associação Portuguesa de Criticos de Teatro)

Preencha e envie este cupão (ou fotocópia do mesmo) para:

Data:

Sinais de cena

Centro de Estudos de Teatro

Faculdade de Letras de Lisboa: sala 67

Alameda da Universidade

1600-214 Lisboa (Portugal) 